\title{
A Hybrid Program Projects Selection Model for Nonprofit TV Stations
}

\author{
Kuei-Lun Chang \\ Department of Communications Management, Ming Chuan University, 250 Zhong Shan N. Road, Section 5, Taipei 111, Taiwan \\ Correspondence should be addressed to Kuei-Lun Chang; cs821@yahoo.com.tw
}

Received 10 August 2014; Revised 11 October 2014; Accepted 16 October 2014

Academic Editor: Bin Shen

Copyright (C) 2015 Kuei-Lun Chang. This is an open access article distributed under the Creative Commons Attribution License, which permits unrestricted use, distribution, and reproduction in any medium, provided the original work is properly cited.

\begin{abstract}
This study develops a hybrid multiple criteria decision making (MCDM) model to select program projects for nonprofit TV stations on the basis of managers' perceptions. By the concept of balanced scorecard (BSC) and corporate social responsibility (CSR), we collect criteria for selecting the best program project. Fuzzy Delphi method, which can lead to better criteria selection, is used to modify criteria. Next, considering the interdependence among the selection criteria, analytic network process (ANP) is then used to obtain the weights of them. To avoid calculation and additional pairwise comparisons of ANP, technique for order preference by similarity to ideal solution (TOPSIS) is used to rank the alternatives. A case study is presented to demonstrate the applicability of the proposed model.
\end{abstract}

\section{Introduction}

Selecting new program projects plays an important role for TV stations. That is because the rating would be influenced by TV programs. The amount and fees of advertising obtained by TV stations would be affected by the rating. The TV stations depend largely on advertising to maintain their operation [1]. Based on Taiwan's TV digitalization policy, there are the dramatic increases in the number of TV programs. Moreover, most people watch TV programs on a daily basis. They now have a great many more TV programs to choose [2]. Hence, selecting the best program project to keep the audiences staying on plays an important role for TV stations. BSC proposed by Kaplan and Norton [3] is widely applied to evaluate business performance. BSC that links financial and nonfinancial, tangible and intangible, and inward and outward factors can provide an integrated and comprehensive viewpoint for decision makers to select the best project.

The purpose of nonprofit organizations is to contribute to and create social value, unlike for-profit organizations whose primary goal is generating economic value. Nonprofit organizations try to support and sustain communities and advance a particular mission through public services and charitable activities. As to media industry, commercial TV stations aim at pleasing audiences to increase audience rating and make a profit. Different from commercial TV stations, nonprofit TV stations are not focused on pursuing for earnings. Their missions are not relied on profit reasons. For nonprofit TV stations, missions are social demands. They obtain resources from the society so that they are able to achieve the missions. They provide access to and participation in public life. Nonprofit TV stations can be instrumental in promoting access to education and culture and developing knowledge. That is the reason why we also add the concept of CSR to select program projects. CSR is defined as a "voluntary corporate commitment to exceed the explicit and implicit obligations imposed on a firm by society's expectations of conventional corporate behavior" [4]. Hou and Reber [5] point out that the financial realities of today's media environment require media outlets to satisfy public interests and shareholders' fiscal expectations. Besides, a social responsible behavior should benefit a firm in many ways, such as a good reputation [6]. Lee et al. [7] also point out that, by engaging in CSR activities, companies obtain a wide range of business benefits. This paper combines the concept of BSC and CSR to collect the criteria for TV program 
projects selection. The fuzzy Delphi method which creates more effective criteria selection is used to modify criteria.

BSC acknowledges the presence of dynamic relationships among the perspectives, which means that the importance of one perspective cannot be determined without knowing the effects of the relationships between it and other perspectives [8]. In other words, the perspectives and criteria of BSC are interrelated. ANP produces more accurate weighting of criteria, since it enables consideration of the dependence among factors in decision-making problems. Unfortunately, ANP requires many pairwise comparisons depending on the number and interdependence of factors and alternatives. This disadvantage of ANP is eliminated via the use of TOPSIS. Thus, the selection process is shortened [9]. By combining fuzzy Delphi method, ANP, and TOPSIS, the system presented in this study can make better TV program projects selection decisions within a shorter time, which distinguishes this study from others in the literature.

\section{Theoretical Background}

2.1. TV Program Projects Selection by MCDM. Investigating previous researches about TV program projects selection, Liao et al. [1] combine BSC with analytic hierarchy process (AHP) to help Taiwanese TV station managers to select new program projects. Hsu et al. [10] use modified Delphi method and AHP to select the Korean dramas for commercial TV stations. Chang [11] utilizes fuzzy Delphi method and ANP to select program projects for Taiwanese commercial TV stations.

As to hierarchy construction, we combine the concept of BSC and CSR to collect the criteria for TV program projects selection. Then, the fuzzy Delphi method is use to identify the selection criteria. The perspectives and criteria of BSC are interrelated. Besides, the assumption of independence of criteria is not always correct because in real world the criteria are often interdependent [12]. In other words, AHP assumes that there are independent relationships among criteria no longer suitable to select TV program projects. About Chang [11], the disadvantage of ANP is eliminated via the use of TOPSIS in this paper. By combining fuzzy Delphi method, ANP, and TOPSIS, this study can make better decisions in TV program projects selection.

2.2. BSC. BSC is originally developed by Kaplan and Norton as a performance measurement tool for managers to obtain a quick and comprehensive view of how their businesses were operating. BSC stresses financial and nonfinancial aspects, long-term and short-term strategies, and external and internal business measures. In other words, BSC adds nonfinancial performance measures to traditional financial metrics to provide managers a more "balanced" view of organizational performance [3]. Through BSC, management can not only communicate well with their employees but also control the progress of strategic development in order to improve organizational performance and to increase competitiveness [13].
BSC contains 4 perspectives including financial, customer, internal business process, and learning and growth. There is a causal relationship among these perspectives. If the learning and growth perspective is improved, then the internal business process perspective will be improved. There is also a positive effect on customer perspective which will have an impact on the financial perspective. The contents of these 4 perspectives are described as follows $[3,14,15]$ :

(1) Financial perspective. Setting up a financial goal and the implementation of executing strategy achievements can be shown in this perspective. The measurements include a return on investment, operating costs, cash flows, and so forth.

(2) Customer perspective. Customers are the source of business profits. Hence, satisfying customer needs is the objective pursued by companies. Organizations should use their advantages and resources to show the differences in comparison with their competitors. The key measurements are customer satisfaction, customer acquirement, and customer profitability.

(3) Internal business process perspective. This perspective refers to the internal organizations' operating process which should be followed, the operating strategy plans presented, and the attempts made to accomplish the customers' and shareholders' expectations.

(4) Learning and growth perspective. For sustainable operation, organizations should rely on continual innovation and growth. Learning and growth perspective is to provide the infrastructure for achieving the objectives of the other 3 perspectives and for creating long-term growth and improvement through systems, employees, and organizational procedures. In any case, learning and growth perspective constitutes the essential foundation for success of organization.

BSC is applied extensively in business and industry, government, and nonprofit organizations worldwide to align business activities to the vision and strategy of the company. In this paper, by reviewing literatures about BSC, we collect criteria to select the best TV program project.

2.3. CSR. The enterprises are the organ of society and their management has to consider the impact of business decisions in order to promote the public good and to contribute to society strength and harmony [16]. What we mentioned above is the concept of CSR. Falck and Heblich [4] also define CSR as a "voluntary corporate commitment to exceed the explicit and implicit obligations imposed on a firm by society's expectations of conventional corporate behavior." CSR is a business approach that considers how company activities impact society. More than economic and financial ones, legal and ethical responsibilities are also taken into account [17]. In other words, CSR that includes not only the business and economic dimensions but also social and environment ones aims to benefit people, communities, and society. Mass media, in their various forms, represent an influential role that actively participates in societal discussions on diverse 
issues. In other words, mass media have the potential to shape people's thinking and behavior [18]. Additionally, nonprofit TV stations are not only focused on pursuing for earnings. Their missions are not only relied on profit reasons. For nonprofit TV stations, missions also include social demands. As the result, we add the concept of CSR to select the best TV program project.

\section{Methodology}

3.1. Fuzzy Delphi Method. Hsu and Yang [19] apply a triangular fuzzy number to encompass expert opinions and establish a fuzzy Delphi method. The max and min value of expert opinions are taken as the 2 terminal points of the triangular fuzzy numbers, and the geometric mean is taken as the membership degree of the triangular fuzzy numbers to derive the statistical unbiased effect and avoid the impact of extreme values. Ma et al. [20] argue that the advantage of fuzzy Delphi method is its simplicity. All the expert opinions can be encompassed in one investigation. Hence, this method can create more effective criteria selection. This paper adopts fuzzy Delphi method to identify the selection criteria for TV program projects. The geometric mean of each criterion is used to denote the consensus of the experts' evaluation value of the criteria.

3.2. ANP. ANP is a comprehensive decision-making technique that captures the outcome of dependency between criteria. The advantage of ANP is that not only it is appropriate for both quantitative and qualitative data types, but it also can overcome the problem of interdependence and feedback [21]. AHP serves as a starting point for ANP. Priorities are established in the same way that they are in AHP, by using pairwise comparisons. ANP comprises 4 major steps [22].

Step 1 (construct hierarchy and structure problem). Structure the problem in a hierarchy of different levels constituting goal, perspective, criteria, and alternatives. The hierarchy, comprising a goal, levels of elements, and connections between the elements, can be determined by decision makers' opinions via brainstorming or other appropriate methods such as literature review.

Step 2 (determine the perspectives and criteria weights). In this step, the decision-making committee makes a series of pairwise comparisons to establish the relative importance of perspectives and criteria. In these comparisons, a 1-9 scale is applied to compare 2 perspectives or criteria according to the interdependency of the perspectives and criteria. The decision makers have to consider such questions as "Which perspective or criteria should be emphasized more?" and "How much more?" The eigenvector of the observable pairwise comparison matrix provides the perspectives and criteria weights at this level, which will be used in the supermatrix. Saaty [23] proposes the consistency ratio (CR) to verify the consistency of the pairwise comparison matrix. If the $C R$ value $\leq 0.1$, the consistency of the pairwise comparison matrix is accepted.
Step 3 (construct and solve the supermatrix). The supermatrix concept is similar to the Markov chain process. The perspectives and criteria weights derived from Step 2 are used to obtain the column of the supermatrix. Finally, the supermatrix is stabilized by multiplying the supermatrix by itself until the supermatrix's row values converge to the same value for each column of the matrix. We call the result the limiting matrix.

Step 4 (select the best alternative). Based on the limiting matrix and weights of alternatives with respect to criteria, we can aggregate the total weight of each alternative. We rank the alternatives according to their priority weights.

ANP is well explored in previous studies. Chang [24] applies ANP and TOPSIS to select new product development (NPD) projects for century-old Taiwanese food firms. In this paper, we use the same approach to a different domain, to select the best TV program project for nonprofit TV stations. However, there are still some other differences. Firstly, nonprofit TV stations are not only focused on pursuing for earnings. Their missions also include social demands. Considering the characteristics of nonprofit TV stations, the concept of CSR is added. In other words, by reviewing studies about BSC and CSR, we collect the selection criteria. Second, fuzzy Delphi method which can create more effective criteria selection is utilized in this paper to modify the criteria. As a result, we can obtain more accurate criteria. Third, the hierarchy of Chang [24] is different from this study. Hsu et al. [25] use decision-making trial and evaluation laboratory (DEMATEL) and ANP to select outsourcing providers. Kabak [26] applies fuzzy DEMATEL-ANP model to select snipers. Shih and Chen [27] present a model for a new product design by a three-stage quality function development (QFD), ANP, and the theory of inventive problem solving (TRIZ). Wang et al. [28] construct a project selection model on the basis of fuzzy Delphi method, interpretive structural modeling (ISM), and ANP. Wu et al. [29] use fuzzy Delphi method, ANP, and TOPSIS to select suppliers. Wu et al. [30] apply fuzzy Delphi method and ANP to select NPD projects. Zareinejad and Javanmard [31] apply ANP, intuitionistic fuzzy set (IFS), and grey relational analysis (GRA) to select third-party reverse logistics providers. They also point out that the unique ability of ANP to analyze the relationships and feedback of factors should not be ignored. Chang [11] utilizes fuzzy Delphi method and ANP to select program projects for Taiwanese commercial TV stations. Chang [32] uses fuzzy Delphi method, ANP, and TOPSIS to help chain cram schools select social media for marketing.

The literature shows that ANP, which is widely applied in decision making, is more accurate and feasible under interdependent situations. The assumption of independence of criteria is not always correct because in real world the criteria are often dependent with each other [12]. Moreover, the perspectives and criteria of BSC are interrelated. ANP appears to be one of the more feasible and accurate solutions for generating the weights of the criteria. 
3.3. TOPSIS. TOPSIS is proposed by Hwang and Yoon in 1981. The main idea comes from the concept of the compromise solution to choose the best alternative nearest to the positive ideal solution $\left(A^{*}\right)$ and farthest from the negative ideal solution $\left(A^{-}\right)[21,33]$. The computation procedure is presented below.

Step 1. Construct the standardized appraisal matrix

$$
r_{i j}=\frac{x_{i j}}{\sqrt{\sum_{i=1}^{m} x_{i j}^{2}}},
$$

where $i$ indicates the alternatives, $j$ denotes the selection criteria, and $x_{i j}$ means the $i$ alternative under the $j$ criterion to be assessed.

Step 2 (construct the weighted standardized appraisal matrix). The weights of selection criteria, $w=$ $\left(w_{1}, w_{2}, \ldots, w_{n}\right)$, multiplied by the standardized appraisal matrix may be expressed as

$$
\begin{aligned}
v & =\left[\begin{array}{cccc}
v_{11} & v_{12} & \ldots & v_{1 n} \\
v_{21} & v_{22} & \ldots & v_{2 n} \\
\vdots & \vdots & \ldots & \vdots \\
v_{m 1} & v_{m 2} & \ldots & v_{n m}
\end{array}\right] \\
& =\left[\begin{array}{cccc}
w_{1} r_{11} & w_{2} r_{12} & \ldots & w_{n} r_{1 n} \\
w_{1} r_{21} & w_{2} r_{22} & \ldots & w_{n} r_{2 n} \\
\vdots & \vdots & \ldots & \vdots \\
w_{1} r_{m 1} & w_{2} r_{m 2} & \ldots & w_{n} r_{m n}
\end{array}\right] .
\end{aligned}
$$

Step 3. Identify the positive ideal solution and negative ideal solution:

$$
\begin{aligned}
A^{*} & =\left\{v_{1}^{*}, v_{2}^{*}, \ldots, v_{j}^{*}, \ldots, v_{n}^{*}\right\} \\
& =\left\{\left(\max _{i} v_{i j} \mid j \in J\right) \mid i=1, \ldots, m\right\}, \\
A^{-} & =\left\{v_{1}^{-}, v_{2}^{-}, \ldots, v_{j}^{-}, \ldots, v_{n}^{-}\right\} \\
& =\left\{\left(\min _{i} v_{i j} \mid j \in J\right) \mid i=1, \ldots, m\right\} .
\end{aligned}
$$

Step 4. Calculate the Euclidean distance between the positive ideal solution $\left(S_{i}^{*}\right)$ and negative ideal solution $\left(S_{i}^{-}\right)$for each alternative:

$$
\begin{aligned}
& S_{i}^{*}=\sqrt{\sum_{j=1}^{n}\left(v_{i j}-v_{i}^{*}\right)^{2}}, \quad i=1, \ldots, m, \\
& S_{i}^{-}=\sqrt{\sum_{j=1}^{n}\left(v_{i j}-v_{i}^{-}\right)^{2}}, \quad i=1, \ldots, m .
\end{aligned}
$$

Step 5. Calculate the relative closeness to the positive ideal solution for each alternative:

$$
C_{i}^{*}=\frac{S_{i}^{-}}{S_{i}^{*}+S_{i}^{-}} .
$$

An alternative $A_{i}$ is closer to $A^{*}$ and farther from $A^{-}$as $C_{i}^{*}$ approaches 1 .

Step 6 (rank the preference order by $C_{i}^{*}$ ). According to $C_{i}^{*}$, larger index values indicate better performance of the alternatives.

In the literature about TOPSIS, Chang [24] applies ANP and TOPSIS to select NPD projects. Ishizaka et al. [34] select the location of a casino in the Greater London region using the Weighted Sum Method, TOPSIS, and the preference ranking organization method for enrichment evaluation (PROMETHEE). Wu et al. [29] use fuzzy Delphi method, ANP, and TOPSIS to select suppliers. Chang [32] uses fuzzy Delphi method, ANP, and TOPSIS to help chain cram schools select social media for marketing. Although TOPSIS is comprehensible and the computations are uncomplicated, it suffers from the inherent problem of assigning reliable subjective preferences to criteria [35]. Velasquez and Hester [36] also point out that the disadvantage of TOPSIS is that it is difficult to weight. Due to the interdependent criteria, ANP is applied in this paper to generate the weights for the selection criteria. TOPSIS is used to rank the alternatives.

\section{The Implementation of Proposed Model}

We employ fuzzy Delphi method, ANP, and TOPSIS in a nonprofit TV station to select the best TV program project. The decision committee includes 2 senior managers of program department to make decisions. There are 3 projects of drama as alternatives. We depict the selection process as follow.

Step 1 (construct hierarchy and structure problem). By interviewing executives and reviewing studies about BSC and CSR, we collect the criteria. Fuzzy Delphi method can create better criteria selection [20]. Thus, we apply the concept of fuzzy Delphi method to revise the criteria. Questionnaires based on Likert 9-point scale, with 1 as most unimportant and 9 as most important, are sent to 48 senior executives in nonprofit TV stations to obtain their opinions about the importance of criteria. In this paper, the geometric mean of each criterion is used to denote the consensus of the experts' evaluation value of the criteria

$$
L_{G}=\left(L_{1} \times L_{2} \times \cdots \times L_{n}\right)^{1 / n},
$$

where $L_{n}=$ importance rating of the criteria by $n$th experts, while $L_{G}=$ geometric mean value.

According to the geometric mean value of each criterion, we retain top 12 showing in Table 1 . Based on BSC, the hierarchy is constructed for selecting TV program projects, as shown in Figure 1. The overall goal of the hierarchy is to select the best TV program project. Level 1 represents the 4 perspectives for selecting the best TV program project (Learning and growth, Internal business process, Customer, and Financial). Each perspective is decomposed into 3 criteria. Level 3 contains 3 alternatives. The 3 alternatives are stories of volunteers in Tzu Chi Foundation. 
TABLE 1: Descriptions of the selection criteria.

\begin{tabular}{lcc}
\hline Criteria & Definition & Contributors \\
\hline$C_{1}:$ Team & The efficiency of teamwork. & {$[37,38]$} \\
$C_{2}:$ Capability & The capability of employee. & {$[24,30,39]$} \\
$C_{3}:$ Training & The training of employee. & {$[13,38]$} \\
$C_{4}:$ Lead-time & The lead-time of TV program. & {$[24,30]$} \\
$C_{5}:$ Content & The content of TV program. & Executive proposed. \\
$C_{6}:$ Interaction & The interaction with audience. & Executive proposed. \\
$C_{7}:$ Satisfaction & The satisfaction index of audience. & {$[13,37,40]$} \\
$C_{8}:$ Reputation & The reputation of brand. & {$[24,30]$} \\
$C_{9}:$ Public & Public benefit. & {$[6]$} \\
$C_{10}:$ Personnel & The cost of personnel. & {$[41]$} \\
$C_{11}:$ Production & The cost of production. & {$[1]$} \\
$C_{12}:$ Profitability & The profitability of TV program. & {$[24,30]$} \\
\hline
\end{tabular}

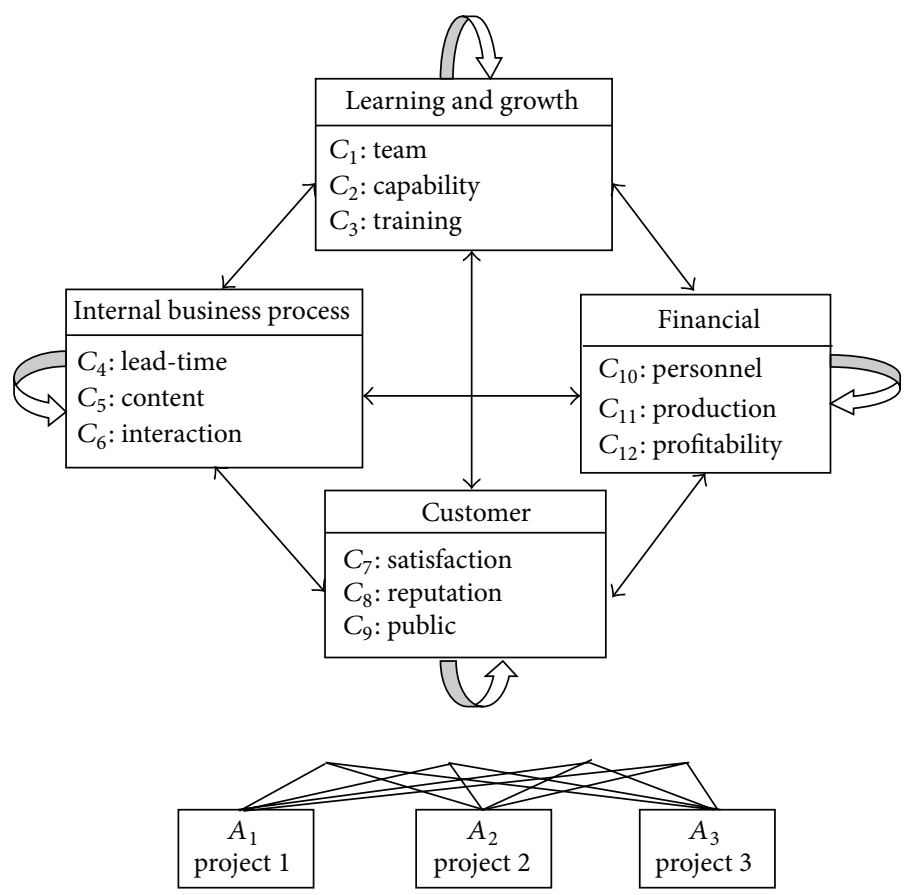

FIGURE 1: The hierarchy to select the best TV program project for nonprofit TV stations.

Step 2 (determine the perspectives and criteria weights). In this step, the decision-making committee makes a series of pairwise comparisons to establish the relative importance of perspectives. In these comparisons, a 1-9 scale is applied to compare the 2 perspectives. The pairwise comparison matrix and the development of each perspective priority weight are shown in Tables $2-5$.

According the interdependency of criteria, we apply pairwise comparisons again to establish the criteria relationships within each perspective. The eigenvector of the observable pairwise comparison matrix provides the criteria weights at this level, which will be used in the supermatrix. With respect to Team, for example, a pairwise comparison within the Financial perspective can be shown in Table 6. According to this way, we can derive every criterion weight to obtain the unweighted supermatrix. The CR of each pairwise comparison is less than 0.1 , which means that the reliability of the data is acceptable.

Step 3 (construct and solve the supermatrix). The unweighted supermatrix derived in Step 2 is shown in Table 7. It is then multiplied by the priority weights from the perspectives illustrated in Tables 2 to 5. After multiplying the unweighted supermatrix and priority weights from the perspectives, the study obtains the weighted supermatrix as shown in Table 8.

For example, $(0.3218,0.6190,0.0592) \times 0.3470=(0.1117$, $0.2148,0.0205)$. In other words, the weights of the criteria are multiplied by the weight of their own perspective to obtain the weighted supermatrix. Finally, the system solution 
TABLE 2: The pairwise comparison and priority weights of the perspectives with respect to Learning and growth.

\begin{tabular}{lccccc}
\hline & Learning and growth & $\begin{array}{c}\text { Internal business process } \\
\lambda_{\max }=4.0079, \mathrm{CR}=0.0026\end{array}$ & Customer & Financial & Priority weights \\
\hline Learning and growth & 1.0000 & 0.2500 & 0.2673 & 0.2041 & 0.0731 \\
Internal business process & 4.0000 & 1.0000 & 1.4142 & 1.0000 & 0.3298 \\
Customer & 3.7417 & 0.7071 & 1.0000 & 0.7071 & 0.2501 \\
Financial & 4.8990 & 1.0000 & 1.4142 & 1.0000 & 0.3470 \\
\hline
\end{tabular}

TABLE 3: The pairwise comparison and priority weights of the perspectives with respect to Internal business process.

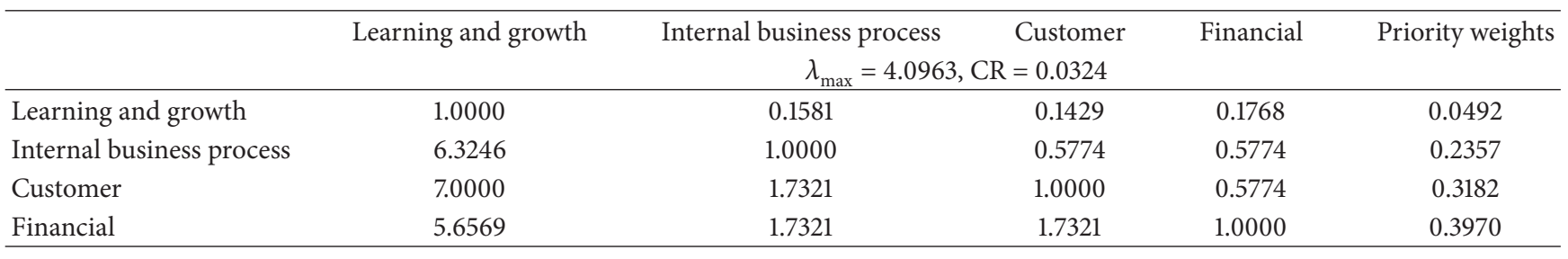

TABLE 4: The pairwise comparison and priority weights of the perspectives with respect to Customer.

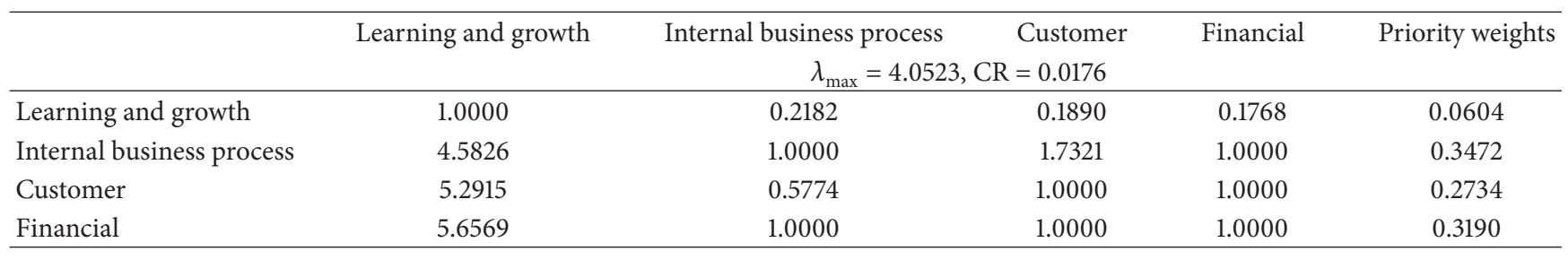

TABLE 5: The pairwise comparison and priority weights of the perspectives with respect to Financial.

\begin{tabular}{|c|c|c|c|c|c|}
\hline & Learning and growth & Internal business process & Customer & Financial & Priority weights \\
\hline & \multicolumn{5}{|c|}{$\lambda_{\max }=4.0581, \mathrm{CR}=0.0195$} \\
\hline Learning and growth & 1.0000 & 0.2357 & 0.1890 & 0.2041 & 0.0648 \\
\hline Internal business process & 4.2426 & 1.0000 & 1.7321 & 1.0000 & 0.3455 \\
\hline Customer & 5.2915 & 0.5774 & 1.0000 & 1.0000 & 0.2775 \\
\hline Financial & 4.8990 & 1.0000 & 1.0000 & 1.0000 & 0.3122 \\
\hline
\end{tabular}

TABLE 6: The pairwise comparison within the Financial perspective with respect to Team.

\begin{tabular}{lcccc}
\hline & Personnel & Production & Profitability & Priority weights \\
& & \multicolumn{2}{c}{$\lambda_{\max }=3.0228, \mathrm{CR}=0.0173$} & 0.3218 \\
Personnel & 1.0000 & 0.4472 & 6.3246 & 0.6190 \\
Production & 2.2361 & 1.0000 & 9.0000 & 0.0592 \\
Profitability & 0.1581 & 0.1111 & 1.0000 & \\
\hline
\end{tabular}

is derived by multiplying the weighted supermatrix of the model variables by itself, which accounts for variable interaction, until the system's row values converge to the same value for each column of the matrix. The study applies this process to yield the limiting matrix as shown in Table 9.

Step 4 (construct the standardized and weighted standardized appraisal matrix). The decision-making committee is asked to establish the appraisal matrix by comparing 3 alternatives with respect to each criterion. After the appraisal matrix is generated, (1) is used to obtain the standardized appraisal matrix, as shown in Table 10. The criteria weights derived from ANP shown in Table 9 are multiplied by the standardized appraisal matrix to obtain the weighted standardized appraisal matrix.

Step 5 (identify the positive ideal solution and negative ideal solution). The positive ideal solution and negative ideal solution are defined according to (3) as

$$
\begin{gathered}
A^{*}=(0.0115,0.0084,0.0154,0.0763,0.0809, \\
0.0223,0.0146,0.0483, \\
0.1068,0.0684,0.1064,0.0211)
\end{gathered}
$$


TABLE 7: The unweighted supermatrix.

\begin{tabular}{cccccccccccccc}
\hline & $C_{1}$ & $C_{2}$ & $C_{3}$ & $C_{4}$ & $C_{5}$ & $C_{6}$ & $C_{7}$ & $C_{8}$ & $C_{9}$ & $C_{10}$ & $C_{11}$ & $C_{12}$ \\
\hline$C_{1}$ & 0.0000 & 0.8333 & 0.7101 & 0.3863 & 0.2604 & 0.3782 & 0.2568 & 0.2774 & 0.3418 & 0.2194 & 0.4186 & 0.1633 \\
$C_{2}$ & 0.2612 & 0.0000 & 0.2899 & 0.1365 & 0.1678 & 0.4463 & 0.3826 & 0.6253 & 0.3406 & 0.1114 & 0.1365 & 0.1100 \\
$C_{3}$ & 0.7388 & 0.1667 & 0.0000 & 0.4772 & 0.5718 & 0.1755 & 0.3605 & 0.0973 & 0.3175 & 0.6692 & 0.4449 & 0.7267 \\
$C_{4}$ & 0.3088 & 0.2610 & 0.2655 & 0.0000 & 0.8333 & 0.3660 & 0.5019 & 0.6525 & 0.2992 & 0.5188 & 0.4485 & 0.2899 \\
$C_{5}$ & 0.6227 & 0.6684 & 0.6651 & 0.8571 & 0.0000 & 0.6340 & 0.3906 & 0.2618 & 0.6241 & 0.3420 & 0.4099 & 0.3551 \\
$C_{6}$ & 0.0685 & 0.0706 & 0.0694 & 0.1429 & 0.1667 & 0.0000 & 0.1075 & 0.0857 & 0.0767 & 0.1391 & 0.1416 & 0.3551 \\
$C_{7}$ & 0.0567 & 0.0603 & 0.0605 & 0.0644 & 0.0628 & 0.0556 & 0.0000 & 0.1000 & 0.1791 & 0.0625 & 0.0605 & 0.0644 \\
$C_{8}$ & 0.2459 & 0.2037 & 0.1850 & 0.1864 & 0.1901 & 0.2657 & 0.1054 & 0.0000 & 0.8209 & 0.2589 & 0.1850 & 0.1689 \\
$C_{9}$ & 0.6974 & 0.7360 & 0.7546 & 0.7492 & 0.7471 & 0.6787 & 0.8946 & 0.9000 & 0.0000 & 0.6786 & 0.7546 & 0.7667 \\
$C_{10}$ & 0.3218 & 0.2926 & 0.5231 & 0.2649 & 0.2926 & 0.2899 & 0.5737 & 0.2601 & 0.2946 & 0.0000 & 0.7760 & 0.1429 \\
$C_{11}$ & 0.6190 & 0.6406 & 0.4028 & 0.6688 & 0.6406 & 0.6379 & 0.3220 & 0.6497 & 0.6429 & 0.8635 & 0.0000 & 0.8571 \\
$C_{12}$ & 0.0592 & 0.0668 & 0.0741 & 0.0663 & 0.0668 & 0.0722 & 0.1043 & 0.0902 & 0.0625 & 0.1365 & 0.2240 & 0.0000 \\
\hline
\end{tabular}

TABLE 8: The weighted supermatrix.

\begin{tabular}{cccccccccccccc}
\hline & $C_{1}$ & $C_{2}$ & $C_{3}$ & $C_{4}$ & $C_{5}$ & $C_{6}$ & $C_{7}$ & $C_{8}$ & $C_{9}$ & $C_{10}$ & $C_{11}$ & $C_{12}$ \\
\hline$C_{1}$ & 0.0000 & 0.0609 & 0.0519 & 0.0190 & 0.0128 & 0.0186 & 0.0155 & 0.0168 & 0.0207 & 0.0142 & 0.0271 & 0.0106 \\
$C_{2}$ & 0.0191 & 0.0000 & 0.0212 & 0.0067 & 0.0082 & 0.0219 & 0.0231 & 0.0378 & 0.0206 & 0.0072 & 0.0088 & 0.0071 \\
$C_{3}$ & 0.0540 & 0.0122 & 0.0000 & 0.0235 & 0.0281 & 0.0086 & 0.0218 & 0.0059 & 0.0192 & 0.0434 & 0.0288 & 0.0471 \\
$C_{4}$ & 0.1019 & 0.0861 & 0.0876 & 0.0000 & 0.1964 & 0.0863 & 0.1742 & 0.2265 & 0.1039 & 0.1793 & 0.1550 & 0.1002 \\
$C_{5}$ & 0.2054 & 0.2205 & 0.2194 & 0.2020 & 0.0000 & 0.1494 & 0.1356 & 0.0909 & 0.2166 & 0.1182 & 0.1416 & 0.1227 \\
$C_{6}$ & 0.0226 & 0.0233 & 0.0229 & 0.0337 & 0.0393 & 0.0000 & 0.0373 & 0.0298 & 0.0266 & 0.0481 & 0.0489 & 0.1227 \\
$C_{7}$ & 0.0142 & 0.0151 & 0.0151 & 0.0205 & 0.0200 & 0.0177 & 0.0000 & 0.0273 & 0.0490 & 0.0173 & 0.0168 & 0.0179 \\
$C_{8}$ & 0.0615 & 0.0510 & 0.0463 & 0.0593 & 0.0605 & 0.0845 & 0.0288 & 0.0000 & 0.2245 & 0.0718 & 0.0513 & 0.0469 \\
$C_{9}$ & 0.1744 & 0.1841 & 0.1887 & 0.2384 & 0.2377 & 0.2159 & 0.2446 & 0.2461 & 0.0000 & 0.1883 & 0.2094 & 0.2127 \\
$C_{10}$ & 0.1117 & 0.1015 & 0.1815 & 0.1051 & 0.1161 & 0.1151 & 0.1830 & 0.0830 & 0.0940 & 0.0000 & 0.2423 & 0.0446 \\
$C_{11}$ & 0.2148 & 0.2223 & 0.1397 & 0.2655 & 0.2543 & 0.2532 & 0.1027 & 0.2072 & 0.2051 & 0.2696 & 0.0000 & 0.2676 \\
$C_{12}$ & 0.0205 & 0.0232 & 0.0257 & 0.0263 & 0.0265 & 0.0287 & 0.0333 & 0.0288 & 0.0199 & 0.0426 & 0.0699 & 0.0000 \\
\hline
\end{tabular}

TABle 9: The limiting matrix.

\begin{tabular}{lccccccccccccc}
\hline & $C_{1}$ & $C_{2}$ & $C_{3}$ & $C_{4}$ & $C_{5}$ & $C_{6}$ & $C_{7}$ & $C_{8}$ & $C_{9}$ & $C_{10}$ & $C_{11}$ & $C_{12}$ \\
\hline$C_{1}$ & 0.0199 & 0.0199 & 0.0199 & 0.0199 & 0.0199 & 0.0199 & 0.0199 & 0.0199 & 0.0199 & 0.0199 & 0.0199 & 0.0199 \\
$C_{2}$ & 0.0140 & 0.0140 & 0.0140 & 0.0140 & 0.0140 & 0.0140 & 0.0140 & 0.0140 & 0.0140 & 0.0140 & 0.0140 & 0.0140 \\
$C_{3}$ & 0.0253 & 0.0253 & 0.0253 & 0.0253 & 0.0253 & 0.0253 & 0.0253 & 0.0253 & 0.0253 & 0.0253 & 0.0253 & 0.0253 \\
$C_{4}$ & 0.1321 & 0.1321 & 0.1321 & 0.1321 & 0.1321 & 0.1321 & 0.1321 & 0.1321 & 0.1321 & 0.1321 & 0.1321 & 0.1321 \\
$C_{5}$ & 0.1401 & 0.1401 & 0.1401 & 0.1401 & 0.1401 & 0.1401 & 0.1401 & 0.1401 & 0.1401 & 0.1401 & 0.1401 & 0.1401 \\
$C_{6}$ & 0.0387 & 0.0387 & 0.0387 & 0.0387 & 0.0387 & 0.0387 & 0.0387 & 0.0387 & 0.0387 & 0.0387 & 0.0387 & 0.0387 \\
$C_{7}$ & 0.0240 & 0.0240 & 0.0240 & 0.0240 & 0.0240 & 0.0240 & 0.0240 & 0.0240 & 0.0240 & 0.0240 & 0.0240 & 0.0240 \\
$C_{8}$ & 0.0836 & 0.0836 & 0.0836 & 0.0836 & 0.0836 & 0.0836 & 0.0836 & 0.0836 & 0.0836 & 0.0836 & 0.0836 & 0.0836 \\
$C_{9}$ & 0.1797 & 0.1797 & 0.1797 & 0.1797 & 0.1797 & 0.1797 & 0.1797 & 0.1797 & 0.1797 & 0.1797 & 0.1797 & 0.1797 \\
$C_{10}$ & 0.1185 & 0.1185 & 0.1185 & 0.1185 & 0.1185 & 0.1185 & 0.1185 & 0.1185 & 0.1185 & 0.1185 & 0.1185 & 0.1185 \\
$C_{11}$ & 0.1893 & 0.1893 & 0.1893 & 0.1893 & 0.1893 & 0.1893 & 0.1893 & 0.1893 & 0.1893 & 0.1893 & 0.1893 & 0.1893 \\
$C_{12}$ & 0.0348 & 0.0348 & 0.0348 & 0.0348 & 0.0348 & 0.0348 & 0.0348 & 0.0348 & 0.0348 & 0.0348 & 0.0348 & 0.0348 \\
\hline
\end{tabular}

TABLE 10: The standardized appraisal matrix.

\begin{tabular}{ccccccccccccc}
\hline & $C_{1}$ & $C_{2}$ & $C_{3}$ & $C_{4}$ & $C_{5}$ & $C_{6}$ & $C_{7}$ & $C_{8}$ & $C_{9}$ & $C_{10}$ & $C_{11}$ & $C_{12}$ \\
\hline$A_{1}$ & 2.2361 & 7.9373 & 2.4495 & 9.0000 & 9.0000 & 9.0000 & 7.4833 & 8.4853 & 6.0000 & 7.4833 & 6.9282 & 6.4807 \\
$A_{2}$ & 2.2361 & 8.4853 & 2.6458 & 9.0000 & 9.0000 & 9.0000 & 6.9282 & 8.4853 & 5.4772 & 7.4833 & 7.4833 & 7.0000 \\
$A_{3}$ & 2.2361 & 7.9373 & 2.4495 & 9.0000 & 9.0000 & 9.0000 & 6.9282 & 8.4853 & 6.0000 & 7.4833 & 6.9282 & 6.4807 \\
\hline
\end{tabular}


TABLE 11: The results of TOPSIS.

\begin{tabular}{ccccc}
\hline & $S_{i}^{*}$ & $S_{i}^{-}$ & $C_{i}^{*}$ & Rank \\
\hline$A_{1}$ & 0.0020 & 0.0127 & 0.8629 & 1 \\
$A_{2}$ & 0.0127 & 0.0020 & 0.1371 & 3 \\
$A_{3}$ & 0.0023 & 0.0126 & 0.8468 & 2 \\
\hline
\end{tabular}

$$
A^{-}=(0.0115,0.0079,0.0142,0.0763,0.0809
$$

0.0223, 0.0135, 0.0483, 0.0975,

$0.0684,0.1149,0.0195)$.

Step 6 (calculate the Euclidean distance between the positive ideal solution and negative ideal solution for each alternative). The Euclidean distance between the positive ideal solution and negative ideal solution for each alternative can be measured by (4).

Step 7 (calculate the relative closeness to the positive ideal solution for each alternative). $C_{i}^{*}$ value of each alternative can be obtained by (5).

Step 8 (rank of alternatives). Based on Table 11, the best TV program project is selected. It is clear that the ranking for the TV program projects is Alternative 1, Alternative 3, and Alternative 2.

\section{Conclusion and Suggestion}

5.1. Conclusion. In this paper, we propose a hybrid TV program projects selection model that integrates fuzzy Delphi method, ANP, and TOPSIS for nonprofit TV stations. By combining fuzzy Delphi method, ANP, and TOPSIS, this study can make better decisions in selecting TV program projects. The methodology contains 4 stages: (1) through interviewing executives and an exhaustive literature review about BSC and CSR to collect the selection criteria, (2) to identify the selection criteria and establish a hierarchy using fuzzy Delphi method, (3) to calculate the importance levels of selection criteria by ANP, and (4) to evaluate alternative solutions by TOPSIS. A case study is conducted to apply the proposed methodology and to guide the case company to select the best TV program project. This selection model will help nonprofit TV stations managers formulate ideal decisions about program projects.

5.2. Contribution. No research article ever selects program projects for nonprofit TV stations by comprehensively qualitative and quantitative analyses of the alternatives. In addition, applying MCDM to select the best TV program project has a great potential since it does not only consider the cost, but also concern numerous aspects of projects. The main contributions of this study are summarized as follows:

(1) The concept of BSC is widely applied for project selection. More than BSC, the concept of CSR is also included to develop a set of selection criteria for TV program projects selection.

(2) Fuzzy Delphi method which can create a better criteria selection is used to revise the criteria. By this way, we can obtain more accurate criteria. The hierarchy would be more tailor-made for the real practice.

(3) To solve the problem of selection criteria interdependency, ANP is used to generate the weights of the criteria. TOPSIS eliminates many procedures that are performed in ANP and enables the system to reach a conclusion in a shorter time.

(4) The hierarchy including 4 perspectives and 12 criteria can help Taiwanese nonprofit TV stations managers to select program projects more effectively.

5.3. Limitation and Future Research. There are several limitations in this study that require further improvement. First, this study is conducted with expert sample groups. A larger sample that brings more explanatory power may have allowed more sophisticated evaluation analysis. Second, we suggest that future research studies incorporate more criteria in order to make more accurate estimates. Third, some criteria could have a qualitative structure or have an uncertain structure which cannot be measured precisely. In such cases, fuzzy numbers can be applied to obtain the evaluation matrix. Follow-up researchers can analyze this topic with the concept of fuzzy sets. Moreover, the relationship among the criteria of CSR is not identified in this paper. DEMATEL can be applied to solve this question in the future. At last, a new study can focus on using another ranking method, such as VlseKriterijumska Optimizacija I Kompromisno Resenje (VIKOR), and compare that with the results of this paper.

\section{Conflict of Interests}

The author declares that there is no conflict of interests regarding the publication of this paper.

\section{Acknowledgments}

The author would like to thank the Ministry of Science and Technology for their support. This research was partly supported by Ministry of Science and Technology under Grant 102-2410-H-130-019.

\section{References}

[1] S. K. Liao, K. T. Chang, W. C. Duan, and K. L. Chang, "New program projects selection for TV companies," Journalism and Mass Communication, vol. 1, no. 2, pp. 115-122, 2011.

[2] J. H. Chang, C. F. Lai, M. S. Wang, and T. Y. Wu, "A cloud-based intelligent TV program recommendation system," Computers and Electrical Engineering, vol. 39, no. 7, pp. 2379-2399, 2013.

[3] R. S. Kaplan and D. P. Norton, "The balanced scorecard: measures that drive performance," Harvard Business Review, vol. 70, no. 1, pp. 71-79, 1992. 
[4] O. Falck and S. Heblich, "Corporate social responsibility: doing well by doing good," Business Horizons, vol. 50, no. 3, pp. 247254, 2007.

[5] J. Hou and B. H. Reber, "Dimensions of disclosures: corporate social responsibility (CSR) reporting by media companies," Public Relations Review, vol. 37, no. 2, pp. 166-168, 2011.

[6] R. Costa and T. Menichini, "A multidimensional approach for CSR assessment: the importance of the stakeholder perception," Expert Systems with Applications, vol. 40, no. 1, pp. 150-161, 2013.

[7] K. Lee, W. Y. Oh, and N. Kim, "Social media for socially responsible firms: analysis of Fortune 500's Twitter profiles and their CSR/CSIR ratings," Journal of Business Ethics, vol. 118, no. 4, pp. 791-806, 2013.

[8] İ. Yüksel and M. Dağdeviren, "Using the fuzzy analytic network process (ANP) for Balanced Scorecard (BSC): a case study for a manufacturing firm," Expert Systems with Applications, vol. 37, no. 2, pp. 1270-1278, 2010.

[9] M. Dağdeviren, "A hybrid multi-criteria decision-making model for personnel selection in manufacturing systems," Journal of Intelligent Manufacturing, vol. 21, no. 4, pp. 451-460, 2010.

[10] P. F. Hsu, S. Y. Lin, and C. W. Tsai, "Optimal selection of Korean dramas for commercial TV stations in Taiwan by using the AHP," International Journal of E-Adoption, vol. 5, no. 2, pp. 1424, 2013.

[11] K. L. Chang, "An integrated decision making model for program projects selection," Pensee, vol. 76, no. 1, pp. 19-24, 2014.

[12] R. Azimi, A. Yazdani-Chamzini, M. M. Fouladgar, E. K. Zavadskas, and M. H. Basiri, "Ranking the strategies of mining sector through ANP and TOPSIS in a SWOT framework," Journal of Business Economics and Management, vol. 12, no. 4, pp. 670-689, 2011.

[13] H. Y. Wu, "Constructing a strategy map for banking institutions with key performance indicators of the balanced scorecard," Evaluation and Program Planning, vol. 35, no. 3, pp. 303-320, 2012.

[14] R. S. Kaplan and D. P. Norton, "Using the balanced scorecard as a strategic management system," Harvard Business Review, vol. 74, no. 1, pp. 75-85, 1996.

[15] R. S. Kaplan and D. P. Norton, The Balanced Scorecard: Translating Strategy into Action, Harvard Business School Press, Boston, Mass, USA, 1996.

[16] P. F. Drucker, The Practice of Management, Harper Perennial, New York, NY, USA, 1954.

[17] M. van Marrewijk, "Concepts and definitions of CSR and corporate sustainability: between agency and communion," Journal of Business Ethics, vol. 44, no. 2-3, pp. 95-105, 2003.

[18] O. Apostol and S. Näsi, " Firm-employee relationships from a social responsibility perspective: developments from communist thinking to market ideology in Romania," Journal of Business Ethics, vol. 119, no. 3, pp. 301-315, 2014.

[19] T. H. Hsu and T. H. Yang, "Application of fuzzy analytic hierarchy process in the selection of advertising media," Journal of Management and Systems, vol. 7, no. 1, pp. 19-40, 2000.

[20] Z. Ma, C. Shao, S. Ma, and Z. Ye, "Constructing road safety performance indicators using Fuzzy Delphi Method and Grey Delphi Method," Expert Systems with Applications, vol. 38, no. 3, pp. 1509-1514, 2011.

[21] G. H. Tzeng and J. J. Huang, Multiple Attribute Decision Making: Methods and Applications, CRC Press, Boca Raton, Fla, USA, 2011.
[22] T. L. Saaty, Decision Making with Dependence and Feedback: The Analytic Network Process, RWS Publication, Pittsburgh, Pa, USA, 1996.

[23] T. L. Saaty, The Analytic Hierarchy Process, McGraw-Hill, New York, NY, USA, 1980.

[24] K. L. Chang, "Combined MCDM approaches for centuryold Taiwanese food firm new product development project selection," British Food Journal, vol. 115, no. 8, pp. 1197-1210, 2013.

[25] C. C. Hsu, J. J. H. Liou, and Y. C. Chuang, "Integrating DANP and modified grey relation theory for the selection of an outsourcing provider," Expert Systems with Applications, vol. 40, no. 6, pp. 2297-2304, 2013.

[26] M. Kabak, "A fuzzy DEMATEL-ANP based multi criteria decision making approach for personnel selection," Journal of Multiple-Valued Logic and Soft Computing, vol. 20, no. 5-6, pp. 571-593, 2013.

[27] H. S. Shih and S. H. Chen, "A conceptual design of a mobile healthcare device-an application of three-stage QFD with ANP and TRIZ," International Journal of Operations Research, vol. 10, no. 2, pp. 80-91, 2013.

[28] W. M. Wang, A. H. I. Lee, L. P. Peng, and Z. L. Wu, "An integrated decision making model for district revitalization and regeneration project selection," Decision Support Systems, vol. 54, no. 2, pp. 1092-1103, 2013.

[29] C. M. Wu, C. L. Hsieh, and K. L. Chang, "A hybrid multiple criteria decision making model for supplier selection," Mathematical Problems in Engineering, vol. 2013, Article ID 324283, 8 pages, 2013.

[30] G. D. Wu, S. K. Liao, C. H. Chiu, and K. L. Chang, "New product development projects selection for Taiwanese centuryold businesses," Life Science Journal, vol. 10, no. 3, pp. 1152-1161, 2013.

[31] M. Zareinejad and H. Javanmard, "Evaluation and selection of a third-party reverse logistics provider using ANP and IFGMCDM methodology," Life Science Journal, vol. 10, no. 6s, pp. 350-355, 2013

[32] K. L. Chang, "A hybrid social media selection model based on fuzzy Delphi method, ANP and TOPSIS," Pensee, vol. 76, no. 1, pp. 108-122, 2014.

[33] C. L. Hwang and K. Yoon, Multiple Attribute Decision Making: Methods and Application, Springer, New York, NY, USA, 1981.

[34] A. Ishizaka, P. Nemery, and K. Lidouh, "Location selection for the construction of a casino in the Greater London region: a triple multi-criteria approach," Tourism Management, vol. 34, pp. 211-220, 2013.

[35] H. J. Shyur, "COTS evaluation using modified TOPSIS and ANP," Applied Mathematics and Computation, vol. 177, no. 1, pp. 251-259, 2006.

[36] M. Velasquez and P. T. Hester, "An analysis of multi-criteria decision making methods," International Journal of Operations Research, vol. 10, no. 2, pp. 56-66, 2013.

[37] Y. C. Tsai and Y. T. Cheng, "Analyzing key performance indicators (KPIs) for e-commerce and Internet marketing of elderly products: a review," Archives of Gerontology and Geriatrics, vol. 55, no. 1, pp. 126-132, 2012.

[38] Q. L. Lin, L. Liu, H. C. Liu, and D. J. Wang, "Integrating hierarchical balanced scorecard with fuzzy linguistic for evaluating operating room performance in hospitals," Expert Systems with Applications, vol. 40, no. 6, pp. 1917-1924, 2013. 
[39] I. L. Wu and C. H. Chang, "Using the balanced scorecard in assessing the performance of e-SCM diffusion: a multi-stage perspective," Decision Support Systems, vol. 52, no. 2, pp. 474485, 2012.

[40] A. V. Bentes, J. Carneiro, J. F. da Silva, and H. Kimura, "Multidimensional assessment of organizational performance: integrating BSC and AHP," Journal of Business Research, vol. 65, no. 12, pp. 1790-1799, 2012.

[41] C. A. F. Amado, S. P. Santos, and P. M. Marques, “ Integrating the data envelopment analysis and the balanced scorecard approaches for enhanced performance assessment," Omega, vol. 40, no. 3, pp. 390-403, 2012. 


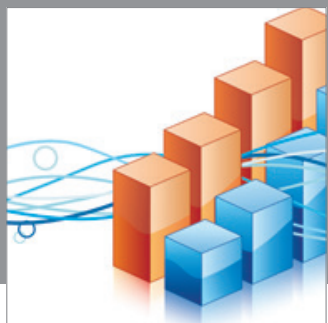

Advances in

Operations Research

mansans

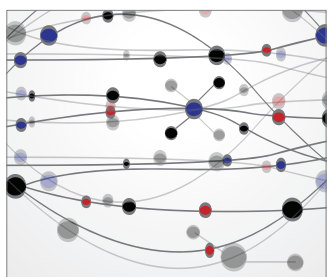

The Scientific World Journal
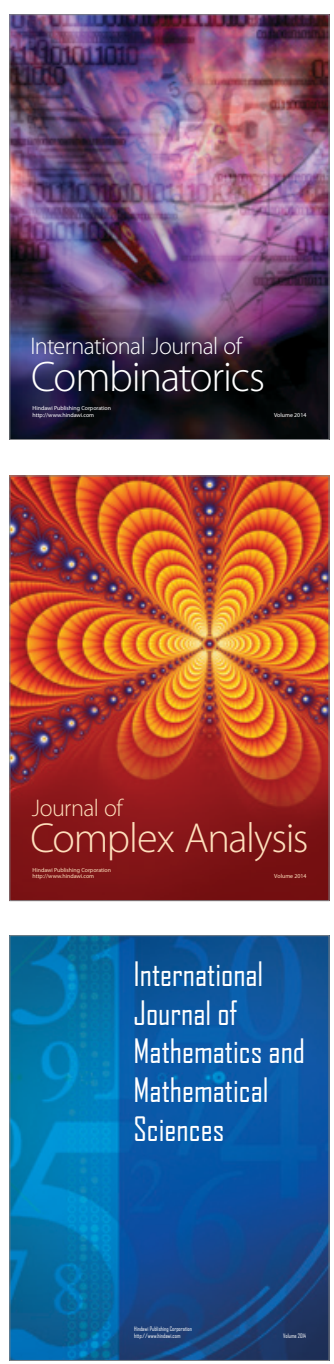
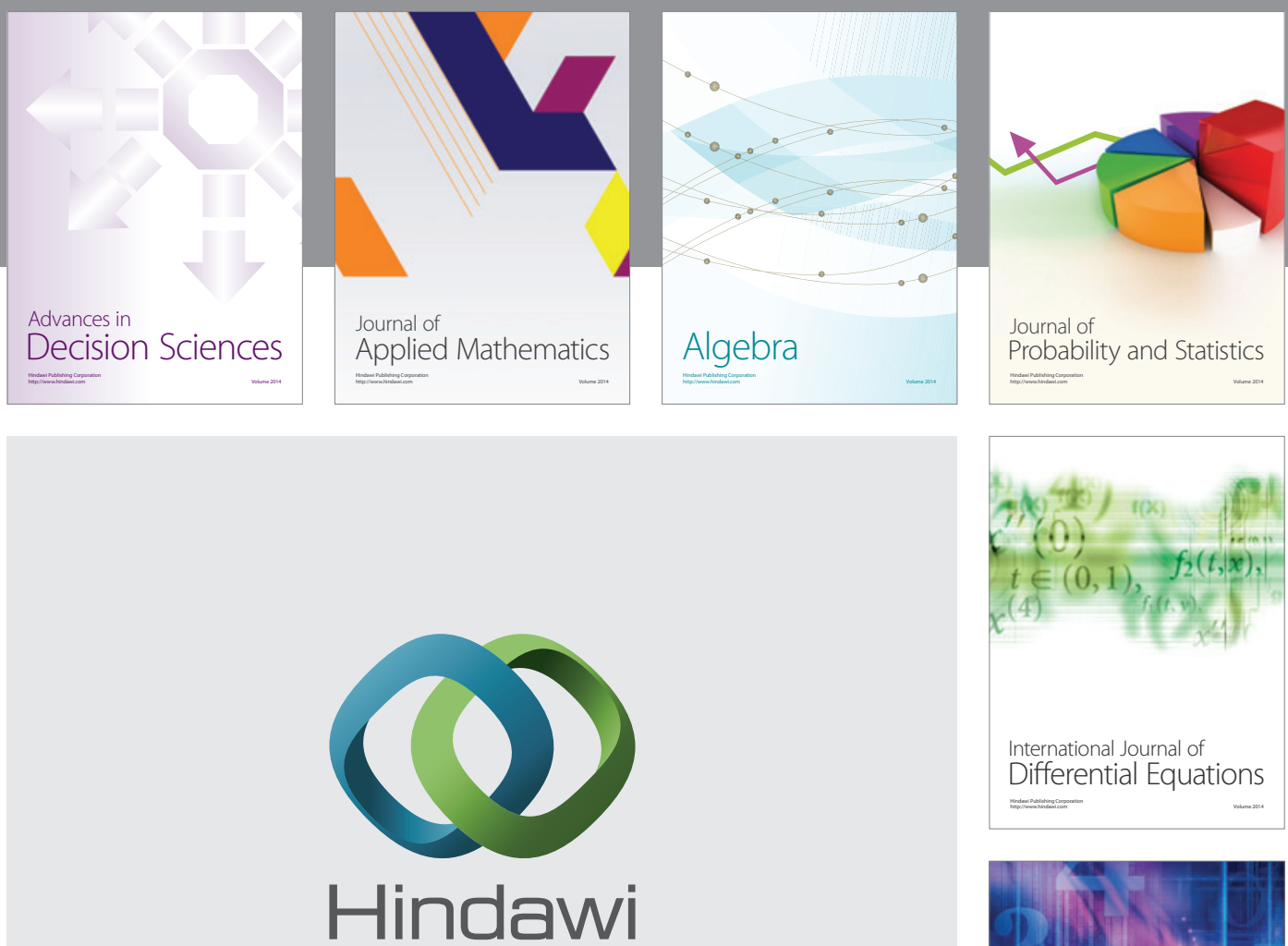

Submit your manuscripts at http://www.hindawi.com
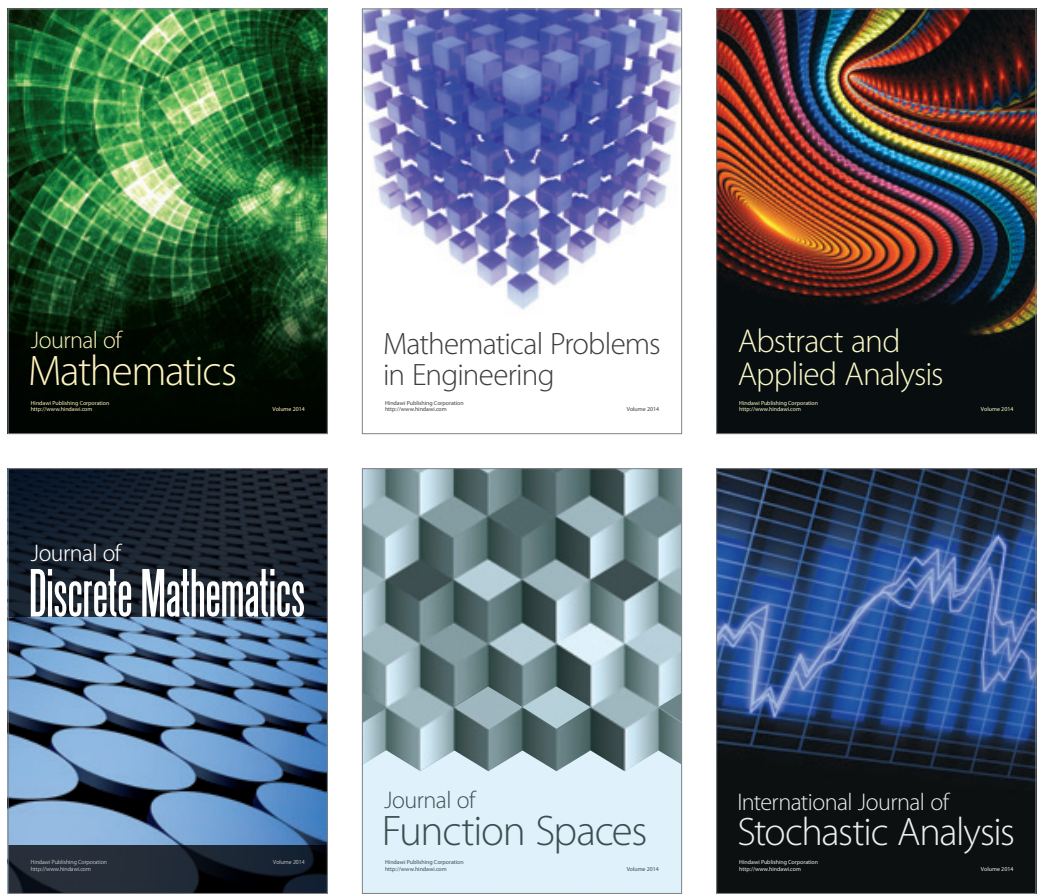

Journal of

Function Spaces

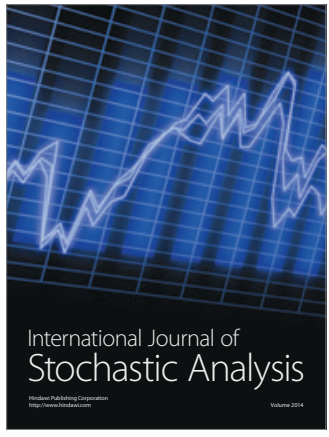

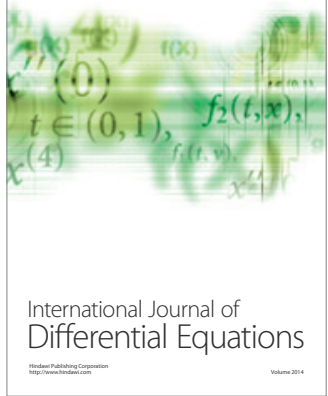
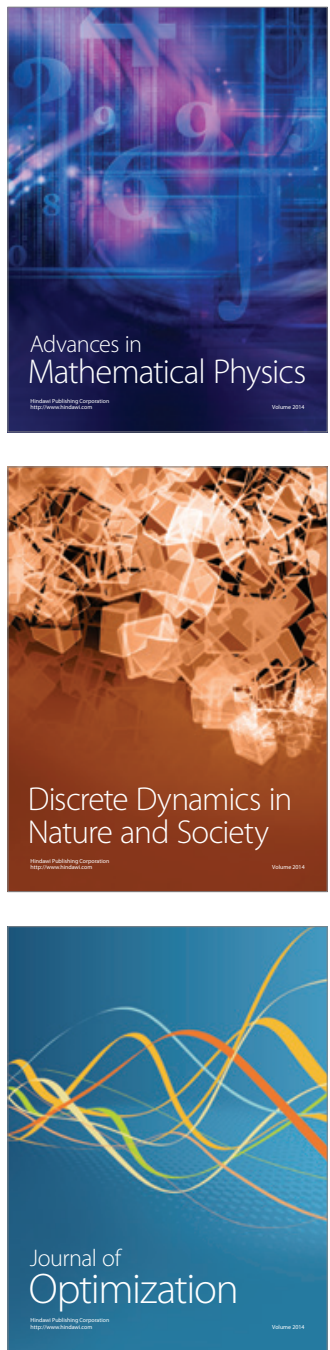